\title{
Reconciling soil-water retention properties and shear strength parameters of compacted clayey soils via suction-controlled ring shear testing
}

\author{
Laureano R. Hoyos ${ }^{1, a}$, Jairo E. Yepes ${ }^{2}$, and Anand J. Puppala ${ }^{3}$ \\ ${ }^{1}$ Professor, University of Texas at Arlington, Arlington, Texas 76019, USA \\ ${ }^{2}$ Teaching Assistant, University of Texas at Arlington, Arlington, Texas 76019, USA \\ ${ }^{3}$ Professor, University of Texas at Arlington, Arlington, Texas 76019, USA
}

\begin{abstract}
A preliminary experimental program has been undertaken to assess suction-controlled peak and residual shear strength properties of a statically compacted, moderate plasticity clayey soil. The experimental program was accomplished in a fully servo/suction-controlled ring shear apparatus, suitable for testing unsaturated soils under large deformations via the axis-translation technique. The test results highlight the important role played by matric suction on residual shear strength behaviour of compacted clayey soils. For the range of net normal stresses and suction states investigated, the increase in peak shear strength with increasing suction was found to be significantly nonlinear for the clayey soil. A distinct correspondence was also observed between the nonlinear nature of peak shear strength envelope, with respect to increasing matric suction, and the soil-water retention curve. The residual failure envelope, however, remains reasonably linear for the range of suction values induced in the present work via axis-translation.
\end{abstract}

\section{Background and importance}

A vast majority of geotechnical infrastructure made of compacted soil, or resting on unsaturated ground, involves a wide range of deformations. Calculation of foundation settlement, for instance, requires a good estimation of soil stiffness at relatively small strains. Analysis of earth slopes, embankments, and soil bearing capacity, on the other hand, requires good estimations of shear strength from peak to residual. Assessment of residual shear strength parameters at relatively low net normal stresses and suction states, as reflected by the range of experimental variables considered in this work, is of critical importance in slope stability analyses involving potentially shallow failures triggered by rainfall at relatively high degrees of saturation. To date, however, there is limited experimental evidence of unsaturated soil behaviour at large deformations as the soil is subjected to controlled suction states. Research efforts have been deterred in the past by the lack of suitable testing tools and techniques. It is in this context that a suctioncontrolled ring shear (RS) apparatus plays a fundamental role in a thorough characterization of this type of materials.

This paper introduces a servo/suction-controlled RS apparatus that is suitable for testing unsaturated soils under large deformations via axis-translation technique. The design of its core system is essentially based upon the original Bromhead ring shear apparatus (Bromhead 1979). A detailed description of its full development, including its main components and thorough performance verification against the original Bromhead device, is presented by Hoyos et al. $(2011,2014)$. The step-by-step assembling process of the RS system can be summarized as follows:

1. The actuators and DA/PC system are switched on to allow the instruments to come into equilibrium and minimize the influence of temperature offsets.

2. A small piece of wet filter paper is placed over the top of 5-bar ceramics, prior to soil compaction, to ensure phase continuity between pore-water in the soil and water in the saturated 5-bar ceramics: Figure 1(a).

3. A $15-\mathrm{mm}(0.59-\mathrm{in})$ thick specimen is statically compacted directly into a bottom annular platen: Figure 1(b). The specimen is then transferred to the RS frame and the platen tightly fixed onto the bottom base plate: Figure 1(c).

4. The vertical load shaft is brought up via a servo controller and the upper annular platen affixed to the top of the piston shaft: Figure 1(c). A vertical sitting load of $25 \mathrm{~N}$ is applied in order to bring the upper platen in full contact with the soil.

5. All drainage and flushing lines are filled with deaired water and flushed several times to avoid any trapped air in the whole system.

6. The main RS cell is set into place and the top cover plate affixed to the cell wall: Figure 1(d). A pore-air pressure $\mathrm{u}_{\mathrm{a}}$ line, from a model PCP-15U panel, is connected to the top RS cover plate via a quick connector.

a Corresponding author: $\underline{\text { hoyos@uta.edu }}$ 
7. Readings of the load-torque transducers are reset while one LVDT and angular deformation sensors are re-zeroed prior to RS testing.

8. The specimen is then subjected either to a suctioncontrolled single-stage or multi-stage RS test using the $\mathrm{s}=\mathrm{u}_{\mathrm{a}}$ testing approach (i.e., $\mathrm{u}_{\mathrm{w}}=0$ ).

9. When the test is finished, all pressures are gradually reduced back to atmospheric pressure and the failure surface examined via microscopic digital imaging. Key items of the isometric view shown in Figure 2 are described by Hoyos et al. (2011).
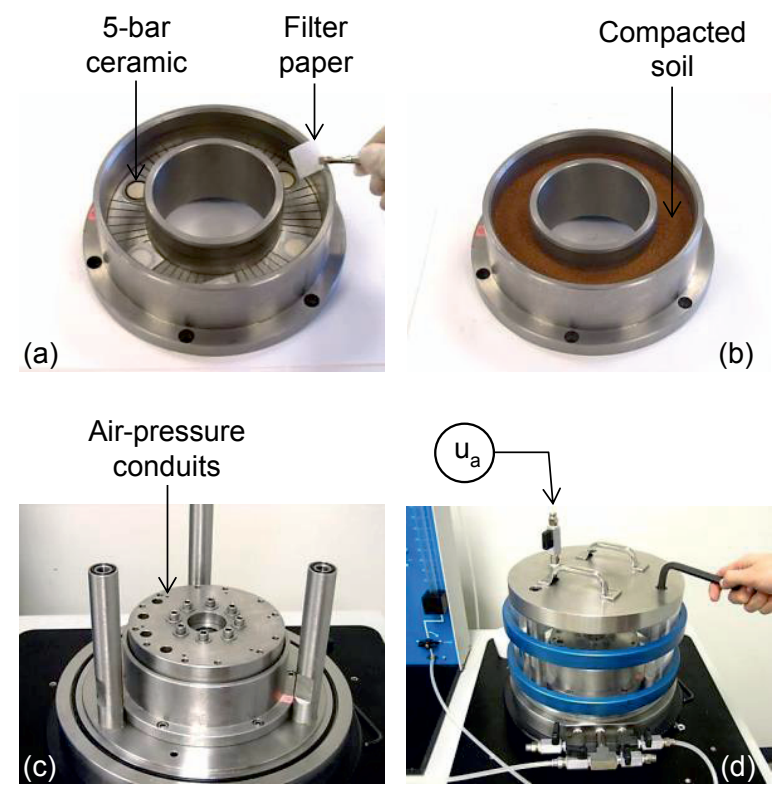

Figure 1. Assembly of suction-controlled RS device: (a) lower platen, (b) test specimen, (c) top platen, (d) main cell.

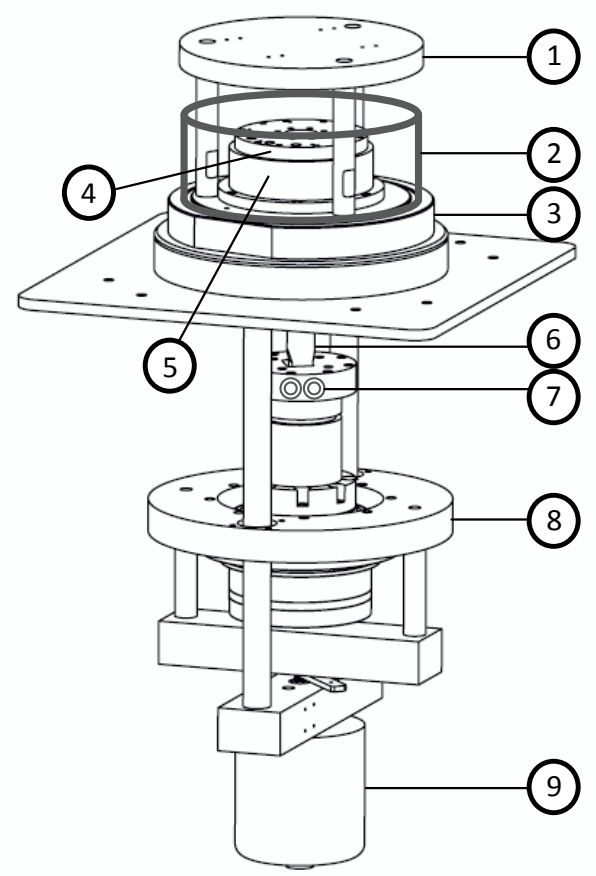

Figure 2. Isometric view of RS core system. (Adapted from Hoyos et al. 2011.)

\section{Test soil and procedures}

The soil used in this investigation classifies as silty clay (CL) according to the USCS, with $18 \%$ sand, $50 \%$ silt, and $32 \%$ clay; maximum dry unit weight, $\gamma_{\mathrm{d}-\max }=1.77$ $\mathrm{g} / \mathrm{cm}^{3}$; optimum moisture content, $\mathrm{OMC}=17 \%$; liquid limit, $\mathrm{LL}=37 \%$; plasticity index, $\mathrm{PI}=20 \%$; and specific gravity, $\mathrm{G}_{\mathrm{s}}=2.72$. During compaction, the upper platen is used to compress one single lift of a loose soil-water mix to target dry unit weight of $95 \%$ of $\gamma_{\mathrm{d}-\max }$ under a constant displacement rate of $1.25 \mathrm{~mm} / \mathrm{min}$, which corresponds to initial degree of saturation of $88 \%$ and matric suction of $100 \mathrm{kPa}$. Further details, including induced compaction energy, are presented by Hoyos et al. $(2011,2014)$.

In the present research work, all suction-controlled RS tests were conducted at an equivalent horizontal shear displacement rate of $0.025 \mathrm{~mm} / \mathrm{min}$ (equivalent to a rotational speed of $0.023^{\circ} / \mathrm{min}$ ), which is slightly lower than that recommended for suction-controlled RS testing on clayey soils (Vaunat et al. 2006, 2007; Infante Sedano et al. 2007). All RS tests were performed by following a multi-stage testing scheme in which all residual strength assessments were made at three or more values of net normal stresses, $\left(\sigma_{\mathrm{n}}-\mathrm{u}_{\mathrm{a}}\right)=25,50,75,100$, and $200 \mathrm{kPa}$; under constant matric suction, $\mathrm{s}=\left(\mathrm{u}_{\mathrm{a}}-\mathrm{u}_{\mathrm{w}}\right)=25,50,75$, 100 , 200, or $300 \mathrm{kPa}$. Shearing was stopped when it was readily apparent that a residual state had been reached.

\section{Soil-water retention properties}

Figure 3 shows the drying loop of the corresponding soilwater retention curves (SWRC) for three different types of intermediate soils considered by the authors for current and future investigations, which have been assessed via both pressure plate and filter paper techniques. The figure also shows the best-fit model curves as per Fredlund and Xing (1994). These SWRCs were obtained to assist the authors in defining the appropriate range of suction states (i.e., beyond the air-entry value of each test soil) to be induced on compacted specimens of CL, SC-SM and SM soils, via the axis-translation technique.

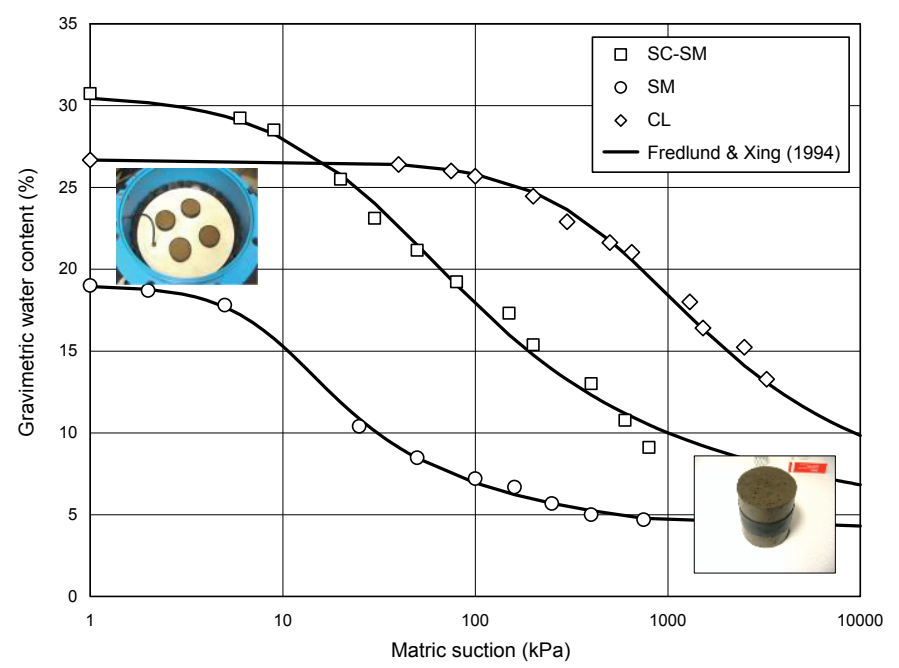

Figure 3. Soil-water retention curves for CL, SC-SM and SM soils via pressure plate and filter paper techniques.

a Corresponding author: 1hoyos@uta.edu 


\section{Shear strength parameters}

Figure 4 shows the shear stress vs. equivalent horizontal shear displacement response of compacted CL soil, during first shearing stage, at matric suctions, $s=75,100$, 200 , and $300 \mathrm{kPa}$; and net normal stress, $\left(\sigma_{\mathrm{n}}-\mathrm{u}_{\mathrm{a}}\right)=25$ $\mathrm{kPa}$. Specimens exhibit a steady increase in shear stress up to a peak value, followed by a gradual decrease until an apparent residual state is attained. The peak is clearly more pronounced at higher suctions. It can also be readily noticed that suction has a significant effect on residual strength, with a considerable increase for $\mathrm{s}=300 \mathrm{kPa}$.

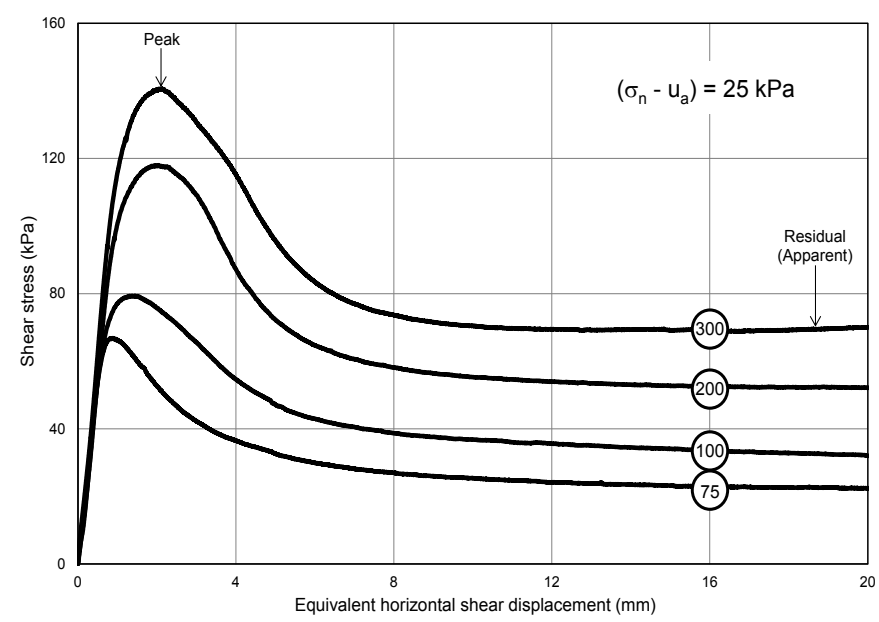

Figure 4. Peak and residual response of CL soil from suctioncontrolled ring shear testing.

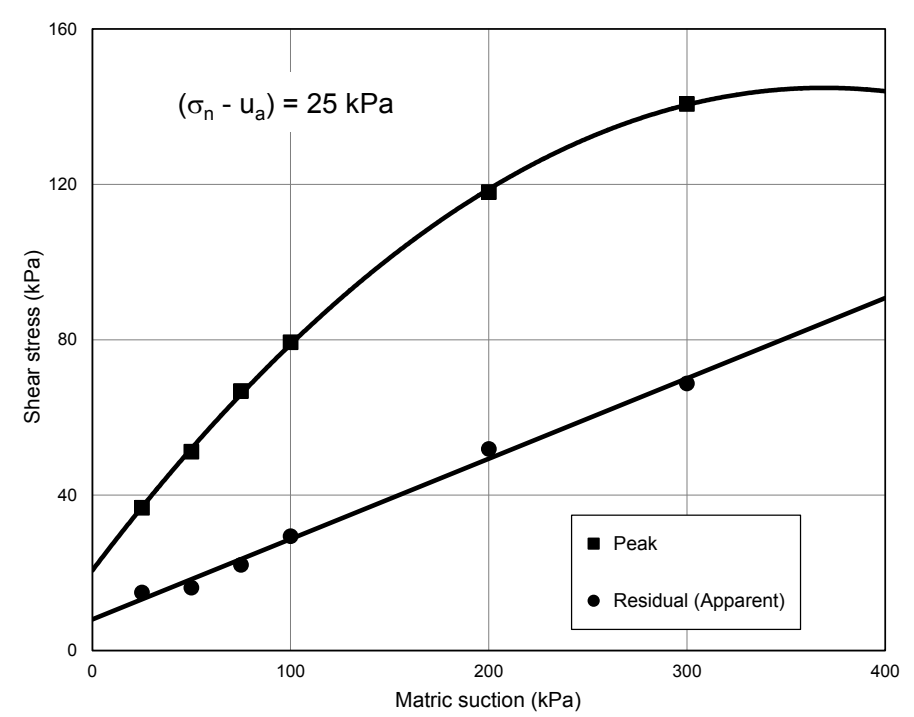

Figure 5. Effect of matric suction on peak and residual failure envelopes from CL soil.

Figure 5 above shows the effect of matric suction on both the peak and the residual failure envelopes obtained from suction-controlled RS testing of compacted CL soil. Results appear to substantiate the direct correspondence that has been observed between the nonlinear nature of peak failure envelopes (threshold value of matric suction beyond which they become nonlinear) and the air-entry value of the test soil as obtained from the SWRC, which is about $100 \mathrm{kPa}$ for CL soil (Fig. 3). The residual failure envelope, however, remains reasonably linear for the range of suction values induced via axis-translation in the present work.

Several authors, including Vanapalli et al. (1996) and $\mathrm{Lu}$ and Likos (2004), consider that there is a direct correspondence between the nonlinear nature of the peak shear strength envelope, with respect to increasing matric suction, and the SWRC. Within the regime of relatively low suction, and prior to the air-entry pressure, the soil pores remain essentially saturated, the shear strength envelope is reasonably linear, and the beta angle $\phi^{b}$ is effectively equal to friction angle $\phi^{\prime}$. As the soil becomes unsaturated, the reduction in the volume of pore-water within this regime effectively reduces the contribution of matric suction toward increasing the shear strength.

This particular feature of hydro-mechanical behaviour of unsaturated soils might provide the most rational basis for understanding the patterns observed in Figures 4 and 5 above.

\section{References}

1. Bromhead, E.N. (1979). "A simple ring shear apparatus." Ground Engineering, 12(5), 40-44.

2. Fredlund, D.G., and Xing, A. (1994). "Equations for the soil-water characteristic curve." Canadian Geotechnical Journal, 31, 521-532.

3. Hoyos, L.R., Velosa, C.L., and Puppala, A.J. (2014). "Residual shear strength of unsaturated soils via suction-controlled ring shear testing." Engineering Geology, Elsevier, 172(2014), 1-11.

4. Hoyos, L.R., Velosa, C.L., and Puppala, A.J. (2011). "A servo/suction-controlled ring shear apparatus for unsaturated soils: Development, performance, and preliminary results." Geotechnical Testing Journal, ASTM, 34(5), 413-423.

5. Infante Sedano, J.A., Vanapalli, S.K., and Garga, V.K. (2007). "Modified ring shear apparatus for unsaturated soil testing." Geotechnical Testing Journal, ASTM, 30(1), 1-9.

6. Lu, N., and Likos, W.J. (2004). Unsaturated soil mechanics, John Wiley \& Sons, Hoboken, N.J.

7. Vanapalli, S.K., Fredlund, D.G., Pufahl, D.E., and Clifton, A.W. (1996). "Model for the prediction of shear strength with respect to soil suction." Canadian Geotechnical Journal, 33(3), 379-392.

8. Vaunat, J., Merchán, V., Romero, E., and Pineda, J. (2007). "Residual strength of clays at high suctions." Proceedings of the Second International Conference on Mechanics of Unsaturated Soils, Weimar, Germany, vol. 2, 151-162.

9. Vaunat, J., Amador, C., Romero, E., and DjerenMaigre, I. (2006). "Residual strength of a low plasticity clay at high suctions." Proceedings of Fourth International Conference on Unsaturated Soils, Carefree, Arizona, vol. 1, 1279-1289.

\footnotetext{
a Corresponding author: 1hoyos@uta.edu
} 